\title{
Effect of various climate databases on the results of dendroclimatic analysis
}

\author{
Roman Sitko ${ }^{1}, J_{a r o s l a v}$ Vido $^{2}$, Jaroslav Škvarenina $^{2}$, Viliam Pichler ${ }^{2}$, Lubomír Scheer $^{1}$, \\ Jana Škvareninová ${ }^{3}$, and Paulína Nalevanková ${ }^{2}$ \\ ${ }^{1}$ Department of Forest Management, Faculty of Forestry, Technical University in Zvolen, \\ T. G. Masaryka 24, 96053 Zvolen, Slovakia \\ ${ }^{2}$ Department of Natural Environment, Faculty of Forestry, Technical University in Zvolen, \\ T. G. Masaryka 24, 96053 Zvolen, Slovakia \\ ${ }^{3}$ Department of Applied Ecology, Faculty of Ecology and Environmental Sciences, Technical University \\ in Zvolen, T. G. Masaryka 24, 96053 Zvolen, Slovakia \\ Correspondence to: Roman Sitko (roman.sitko@tuzvo.sk)
}

Received: 13 July 2015 - Published in Earth Syst. Dynam. Discuss.: 26 August 2015

Revised: 1 April 2016 - Accepted: 5 April 2016 - Published: 26 April 2016

\begin{abstract}
The paper deals with the comparison of the time series drawn from different climate databases. We compared the observed data with the modeled data of monthly and seasonal temperature means and precipitation totals. Reliable and longest available time series of such data represent the basic starting point of dendroclimatic analyses. We evaluated the differences in the growth response of spruce derived using different databases of the considered climatic variables. The stem cores used to derive the cross-correlation function were taken from Hårås locality situated in the boreal zone of the Swedish part of Lapland. We compared the observed records from the nearest weather stations situated $18,40,70$ and $110 \mathrm{~km}$ away from the locality with the interpolated data from four modeled temperature databases and four modeled precipitation databases generated by KNMI Climate Explorer. The spatial resolution of the modeled databases was $0.5^{\circ} \times 0.5^{\circ}$ of latitude and longitude or $1^{\circ} \times 1^{\circ}$ respectively. The evaluation revealed that in all modeled databases systematic errors of different magnitudes occurred. We also found that the radial increments of spruce correlated more tightly with the temperature than with the precipitation in the area of interest. Hence, in the conditions of the boreal zone, temperature could be a more important factor with regard to tree-ring formation. Because of higher spatial variability seen in precipitation data when compared to temperature data, we conclude that the nearest weather station is the most suitable for dendroclimatic analysis leaning on precipitation. Drawing on these results we recommend that the modeled precipitation and temperature databases examined in our study are used for dendroclimatic analyses within areas featuring a sparse network of weather stations.
\end{abstract}

\section{Introduction}

Dendroclimatology as a branch of dendrochronology uses dated ring series to reconstruct the current and past climate (Grudd et al., 2002; Luterbacher et al., 2004; Pauling et al., 2006). Reconstruction of temperature regime through treering series establishes the starting point for the current debate on climate change. Detection of external climatic factors, including changes in orbital solar flow, volcanic erup- tions, greenhouse gases and combinations thereof by means of tree ring series analysis represents a major challenge for interdisciplinary research (Büntgen et al., 2013).

One of the current greatest challenges at the field of forest research is to understand and predict climate change impacts on the development of forest ecosystems. This covers systematic monitoring and detection of climate change, the study of growing response of tree species to ongoing climate change, evaluation of climate models, their calibra- 
tion and creation of climate scenarios, while climate variability affects many natural and anthropogenic systems. Due to this, the need has arisen to create standard climate databases for different climate elements that would cover the vast area of the Earth. In dendroclimatology, monthly and seasonal databases of climate elements are mainly used. Several databases have been created for different primary and secondary climate variables (Mitchell and Jones, 2005).

In dendroclimatological studies dealing with the growth responses of tree species to main climatic factors, i.e. temperature and precipitation (e.g. Babst et al., 2013; Büntgen et al., 2007; Gouirand et al., 2007; Wang et al., 2013), the worldwide database created by the Climatic Research Unit (hereafter as CRU), which belongs to the University of East Anglia, is frequently used. Main data sources for this database are (Harris et al., 2014):

- CLIMAT reports, quality-controlled monthly means and/or totals distributed via WMO-GTS

- Monthly Climatic Data for the World (MCDW), created by the National Climatic Data Center (NCDC) for WMO

- World Weather Records (WWR) - 10-year long databases, which are swapped between the National Meteorological Services (NMSs) and NCDC

- The Australian Bureau of Meteorology (BoM).

Besides the mentioned CRU database there are numerous other gridded databases with a monthly step of climate time series, eg.: HadCRUT4 (Cowtan and Way, 2014), GISS (Hansen et al., 2010), GPCC (Schneider et al., 2015), E-OBS (Haylock et al., 2008), as well as seasonal climatic databases, eg.: Luterbacher et al. Temperature (Luterbacher et al., 2004) and Pauling et al. Precipitation (Pauling et al., 2006), that are more or less suitable for the dendroclimatic analysis.

In dendroclimatological applications the selection of climate data is necessary for the unambiguous explanation of climate impact on the creation of tree radial increment. It is important that these data reflect real conditions under which the increment was created. However, considering the density of weather stations and the variability of meteorological elements conditioned mainly by the morphological roughness of the terrain, this condition cannot always be met.

At this context, precipitation is characterized by much higher spatial variability than temperature, and many more sites are required for reliable spatial precipitation reconstructions, whereas relatively robust spatial temperature estimates can be generated from only a couple of well-located proxy records (Büntgen et al., 2010).

The main objective of this work is to compare the various gridded databases of modeled temperature as well as precipitation data with observed data from an array of the nearest weather stations. The essential question was to analyze the influence of different sources of climatic data on explaining the formation of radial increment of spruce. From this point of view, measured tree ring widths are considered as reference data.

Our study addressed three hypotheses:

i. The Swedish part of Lapland over the polar circle is an appropriate locality for extraction of significant climatic signal from tree rings dendrochronologies of spruce for the main climatic variables, i.e. temperature and precipitation. It is an area dominated by the temperature signal.

ii. The nearest weather station to locality of radial increment formation is the most appropriate for dendroclimatic growing response analysis.

iii. Gridded data sets of temperature and precipitation are appropriate enough for extracting existing significant climatic signal by dendroclimatic growing response analysis in areas with a sparse network of weather stations. There are no significant differences between gridded and observed data sets.

\section{Materials and methods}

Our data were collected at Hårås, a hilly locality situated in the Swedish part of Lapland. Hårås is located $60 \mathrm{~km}$ north of the Arctic Circle border in Norrbotten region, $70 \mathrm{~km}$ west of Jokkmokk town. Its elevation is around $585 \mathrm{~m}$ a.s.l. Orographically, Hårås belongs to the Scandinavian Mountains. Its soil can be classified as Podsol. Location of study area at the Swedish part of Lapland is shown in Fig. 1.

Regarding tree species composition, Pinus sylvestris and Picea excelsa dominate in local forest stands. As the elevation increases, tree canopy opens up and the share of Betula sp. in species composition increases. The upper tree line at an elevation of around $715 \mathrm{~m}$ a.s.l. is formed by pure birch stands.

\subsection{Climate of study area}

According to the Köppen-Geiger climate classification (Kottek et al., 2006), the locality belongs to the subpolar climate Dfc. (snow zone, fully humid with cool summer) and it features long, usually very cold winters, and short, cool to mild summers. Based on the observed meteorological data from the Kvikkjokk station (between the years 1890 and 2001), the Walter climate diagram was constructed in order to express the climate features in the area (Fig. 2).

As shown in the Fig. 2, the climate at locality is rather humid. Annual precipitation is $581 \mathrm{~mm}$. Minimum precipitation sum is observed in March and April $(28 \mathrm{~mm})$ and maximum in July $(86 \mathrm{~mm})$, respectively. Annual average of temperature is $-1.2^{\circ} \mathrm{C}$. Maximum monthly average temperature is observed in July $\left(16.8^{\circ} \mathrm{C}\right)$, while the minimum takes place in January $\left(-13.9^{\circ} \mathrm{C}\right)$ respectively. The coldest monthly average temperature was recorded in January $1893\left(-24.4^{\circ} \mathrm{C}\right)$ 


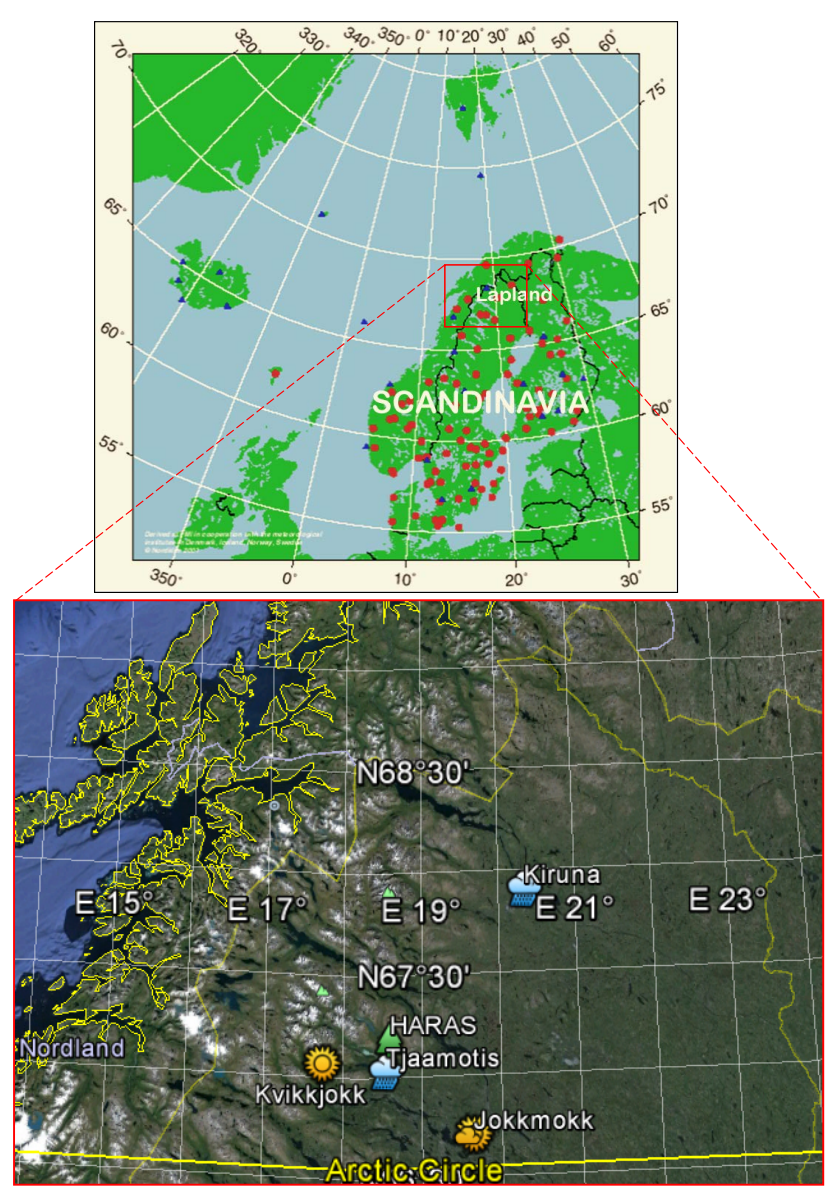

Figure 1. Location of Hårås plot, Kvikkjokk, Tjåmotis and Kiruna meteorological stations in the Swedish part of Lapland. Meteostation map of the NORDKLIM database: stations with data series longer than 90 years, shorter than 90 years (modified from: Tuomenvirta et al., 2001).

and the maximum average monthly temperature was observed in July $1937\left(16.8^{\circ} \mathrm{C}\right)$. Because of the humid climate and a relatively low average air temperature due to energy balance of high latitudes, it is anticipated that air temperature represents the main climate driver for ecological processes in the studied area. This is confirmed also by Holtmeier and Broll (2005).

\subsection{Climate databases}

Two groups of databases were assessed in the study. The first one - NORDKLIM is the database of observed climate data. Three data sets of temperature records and six sets for the precipitation records, recorded on the four weather stations situated close to the locality Hårås, were used for comparison.

The second group included eight data sets generated from five gridded databases. The data from this group are hereinafter called modeled data set. The four modeled data sets of

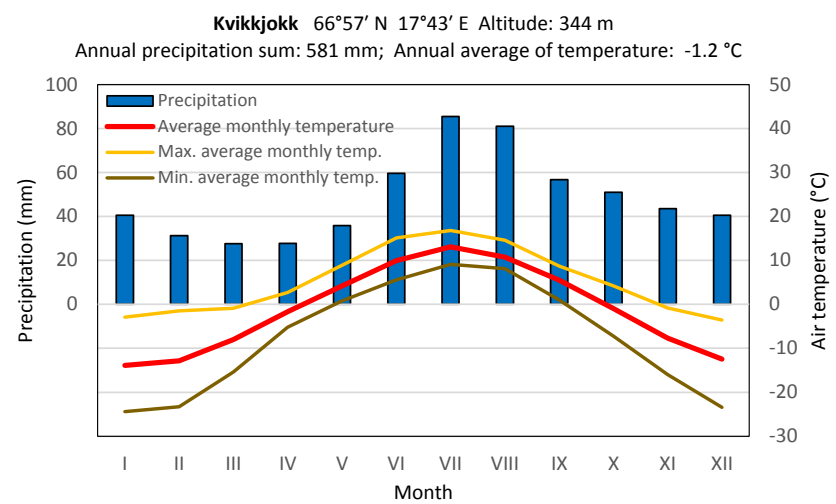

Figure 2. Walter climate diagram for the station Kvikkjokk (time period 1890-2001).

temperature were generated from various gridded databases and another four modeled data sets for precipitation.

For both groups of data sets the monthly and seasonal (3 months) temperature means and monthly and seasonal precipitation totals were assessed. All database properties and labels (abbreviations) of assessed data sets are specified in Table 1.

The NORDKLIM database contains homogenized data sets for 12 climate variables, recorded on 114 weather stations distributed in Scandinavian countries, 48 of which are in Sweden Fig. 1. The database was compiled by the Swedish Meteorological and Hydrobiological Institute (Tuomenvirta et al., 2001). Two weather stations (Kvikkjokk and Jokkmokk) located 40 and $70 \mathrm{~km}$ away from locality Hårås and two other stations (Tjaamotis and Kiruna), located 18 and $110 \mathrm{~km}$ from it, were selected. For Tjaamotis and Kiruna only precipitation data sets (P18, P18 agr, P110, $\left.\mathrm{P} 110_{\text {agr }}\right)$ were provided for the above-mentioned database and both variables (temperature and precipitation data sets) were available for Kvikkjokk and Jokkmokk stations (T40, $\mathrm{T} 40_{\text {agr }}, \mathrm{P} 40, \mathrm{~T} 70, \mathrm{P} 70$ ).

The second group of climate databases included gridded time series. For the position of both the nearest weather stations and Hårås locality, we generated the data using the web application of the Royal Netherlands Meteorological Institute called KNMI Climate Explorer, which was created in order to enable the statistics analysis of time series of climate data (CLIMEX.KNMI, 2014). One can set the location for required climate time series by coordinates for point, or for points defining rectangular area, or by shapefile to define an irregular polygon mask. Average values or a set of grid points can be selected as an output for areas, whereas percentage of valid points for averaging and land/sea mask are optional. That application enables us to apply monthly or yearly high and/or low-pass filter and aggregates data to a lower time resolution. Other useful tools are the construction of statistical forecast model, the computation of anomalies, and the zonal mean. 
Table 1. Properties of climatic databases and labels (abbreviations) of evaluated data sets.

\begin{tabular}{|c|c|c|c|c|c|}
\hline & \multirow{3}{*}{$\begin{array}{c}\text { Database properties } \\
\text { Name }^{1}, \text { Location/Distance/Grid, References }\end{array}$} & \multicolumn{4}{|c|}{ Label of the data sets } \\
\hline & & \multicolumn{2}{|c|}{$\begin{array}{l}\text { Temperature } \\
(1902-2001)\end{array}$} & \multicolumn{2}{|c|}{$\begin{array}{l}\text { Precipitation } \\
(1910-1997)\end{array}$} \\
\hline & & Month & Season & Month & Season \\
\hline $\begin{array}{l}\vec{D} \\
己_{0}^{0} \\
0 \\
0\end{array}$ & $\begin{array}{l}2, \text { Tjaamotis }\left(66^{\circ} 55^{\prime} \mathrm{N} 18^{\circ} 32^{\prime} \mathrm{E}\right) / 18 \mathrm{~km},{ }^{3} \\
2, \text { Kvikkjokk }\left(66^{\circ} 57^{\prime} \mathrm{N} 17^{\circ} 44^{\prime} \mathrm{E}\right) / 40 \mathrm{~km},{ }^{3} \\
2, \text { Jokkmokk }\left(66^{\circ} 37^{\prime} \mathrm{N} 19^{\circ} 38^{\prime} \mathrm{E}\right) / 70 \mathrm{~km},{ }^{3} \\
{ }^{2}, \text { Kiruna }\left(67^{\circ} 49^{\prime} \mathrm{N} 20^{\circ} 20^{\prime} \mathrm{E}\right) / 110 \mathrm{~km},{ }^{3}\end{array}$ & $\begin{array}{l}- \\
\text { T40 } \\
\text { T70 } \\
-\end{array}$ & $\begin{array}{l}- \\
\text { T40 agr } \\
- \\
-\end{array}$ & $\begin{array}{l}\text { P18 } \\
\text { P40 } \\
\text { P70 } \\
\text { P110 }\end{array}$ & $\begin{array}{l}\text { P18agr } \\
- \\
- \\
\text { P110agr }\end{array}$ \\
\hline $\begin{array}{l}\frac{\partial}{0} \\
\frac{0}{0} \\
\dot{0}\end{array}$ & $\begin{array}{l}\text { CRU TS } 3.23,0.5^{\circ} \text {, Harris et al. (2014) } \\
\text { GISS } 250 \mathrm{~T} 2 \mathrm{~m} / \mathrm{SST} \text { anom, } 1^{\circ} \text {, Hansen et al. (2010) } \\
\text { Luterbacher et al. Temperature, } 0.5^{\circ} \text {, Luterbacher et al. (2004) } \\
\text { GPCC V7 } 0.5,0.5^{\circ} \text {, Schneider et al. (2015) } \\
\text { Pauling et al. Precipitation, } 0.5^{\circ} \text {, Pauling et al. (2006) }\end{array}$ & $\begin{array}{l}\text { T_CRU } \\
\text { GISS } \\
- \\
- \\
-\end{array}$ & $\begin{array}{l}\text { T_CRU } \\
- \\
\text { LT } \\
- \\
-\end{array}$ & $\begin{array}{l}\text { P_CRU } \\
- \\
- \\
\text { GPCC } \\
-\end{array}$ & $\begin{array}{l}\text { P_CRU }{ }_{\text {agr }} \\
- \\
- \\
- \\
\text { PP }\end{array}$ \\
\hline
\end{tabular}

${ }^{1}$ Names of modeled databases related to Climexp.KNMI (2014), ${ }^{2}$ NORDKLIM, ${ }^{3}$ Tuomenvirta et al. (2001).

For monthly temperature means data from CRU TS 3.21 database (T_CRU) and anomalies from GISS $250 \mathrm{~T} 2 \mathrm{~m} / \mathrm{SST}$ anom (GISS) with grid resolution 0.5 and $1^{\circ}$, respectively, were generated. The anomaly is a difference between the absolute temperature value and the value of the long-term average determined from the reference period. Seasonal temperature was generated from Luterbacher et al. (2004) database (LT) as well as another one data set was derived by aggregation of CRU TS 3.21 (T_CRUagr). The period overlap for all temperature databases was 100 years (between 1902 and 2001).

Monthly precipitation data sets were generated from GPCC V7 $0.5^{\circ}$ (GPCC), CRU 3.21 database (P_CRU), as well as from Pauling et al. (2008; PP) and aggregated CRU 3.21 database (P_CRUagr) for seasonal precipitation data sets. The assessed period for which all precipitation data sets were available extends from 1910 till 1997, i.e. 88 years. Grid resolution of all utilized precipitation gridded databases is $0.5^{\circ}$.

\subsection{Building mean tree-ring chronology}

At Hårås locality, 20 increment cores were taken from spruce tree stems at a height of $1.3 \mathrm{~m}$. After pre-processing of samples, they were analyzed in WinDENDRO computer image analysis system. The analysis consisted of measuring tree-ring widths and their dating. The created tree-ring series were synchronized with the regional curve derived from the tree-ring series, which showed the highest correlation. We used visual synchronization supported by a graphical method known as "skeleton plot" (Cropper, 1979). The series was considered to be satisfactorily synchronized if the value of coefficient of parallelism (GLK) exceeded $70 \%$. Tree-ring series, which did not exceed this threshold, were excluded from further analyses. The occurrence of poten- tial misdating of tree-ring series was evaluated by the software COFECHA (Grissino-Mayer, 2001). With regard to the open crown canopy of the stands, the high-frequency signal of mean chronology was detrended using a modified negative exponential function. The final tree-ring chronology was performed with the method of robust double-weightedaveraging of tree ring indices that included the removal of temporal autocorrelation. The values of tree-ring indices were calculated using the formula of Cook and Kariukstis (1990). Basic descriptive statistics were calculated to assess the potential of measured tree ring series for its accurate dating and for extraction of climatic signal.

\subsection{Statistical evaluation}

The comparison of climate databases gives us information about the systematic and random error of the modeled climate data. As reference data observed data sets of temperature means and precipitation totals were used, which were recorded at the weather stations and located the closest to Hårås, i.e. Tjaamotis and Kvikkjokk. For these locations were generated modeled data sets from gridded databases. From the differences between the modeled and observed data we calculated the mean error $(\bar{e})$ and the standard error (SE). Student $t$ test was applied to test the significance of the systematic error at 5 and $1 \%$ significance levels. The final accuracy of the modeled data was quantified by root mean square error (RMSE). The above-described evaluation was performed separately for the mean temperature and precipitation totals and separately for monthly and seasonal climatic data sets. The observed seasonal data were derived by aggregating the observed monthly records.

The impact of climate on increment formation was evaluated by deriving the cross-correlation function between monthly or seasonal series of climate variables (tempera- 
Table 2. Statistical evaluation of the differences between the observed and modeled data of monthly and seasonal temperatures (* significant value at $\alpha=1 \%$ ). T40 data set is used as reference data.

\begin{tabular}{lllll}
\hline & \multicolumn{4}{c}{ Temperature } \\
\cline { 2 - 5 } & T_CRU & GISS & T_CRUagr & LT \\
\hline Mean bias $\left[{ }^{\circ} \mathrm{C}\right]$ & $-1.43^{*}$ & $-0.15^{*}$ & $-1.43^{*}$ & $-1.39^{*}$ \\
Mean error $\left[{ }^{\circ} \mathrm{C}\right]$ & \pm 0.69 & \pm 1.56 & \pm 1.17 & \pm 1.19 \\
Mean quadratic error $\left[{ }^{\circ} \mathrm{C}\right]$ & \pm 1.59 & \pm 1.57 & \pm 1.85 & \pm 1.83 \\
\hline
\end{tabular}

Table 3. Statistical evaluation of the differences between the observed and modeled data of monthly and seasonal precipitation totals $(*$ significant value at $\alpha=1 \%$ ). P18 data set is used as reference data.

\begin{tabular}{lllll}
\hline & \multicolumn{4}{c}{ Precipitation } \\
\cline { 2 - 5 } & P_CRU & GPCC & P_CRUagr & PP \\
\hline Mean bias [mm] & $4.62^{*}$ & $-0.73^{*}$ & $14.1^{*}$ & $15.75^{*}$ \\
Mean error [mm] & \pm 5.12 & \pm 6.77 & \pm 17.05 & \pm 31.84 \\
Mean quadratic error [mm] & \pm 6.90 & \pm 6.81 & \pm 22.07 & \pm 35.52 \\
\hline
\end{tabular}

ture, precipitation) and tree-ring indices within an 18-month long (April_preceding year to September) or a 7-season long (March-April-May_preceding year to September-OctoberNovember) dendroclimatic year. Student $t$ test was used to evaluate the significance of the coefficients of correlation at 5 and $1 \%$ significance level. With regard to the objective of the study, we compared the results of growth response derived from the observed climate data and from the modeled climate data sets. We wanted to reveal the cases with different statistical significance of correlation coefficients compared to $\rho=0$, caused by different climate databases and the significant differences between correlation coefficients derived for the same month or season, however using various climate databases. For evaluations thus created, regional tree ring chronology was considered as a reference data set.

\section{Results}

The results are subdivided to two sections, as they answer four groups of questions.

\subsection{Comparison of climate databases}

Question 1: what is the bias, precision, and overall accuracy of modeled data sets at the location of a weather station for monthly and/or seasonal average temperature and precipitation totals?

The differences between the modeled and observed climate data were calculated separately for monthly and seasonal data of mean temperatures and precipitation totals. We analyzed the significance of deviation of the modeled data from the observed records, the presence of the random error and the overall accuracy of the modeled data. Presented statistics are valid for the specific combination of reference observed data and grid point of modeled data. It is due to a different scale of climatic information received by observed and modeled data. The grid point of modeled data represent the same climatic value for the whole cell of grid (area $0.5^{\circ} \times 0.5^{\circ}$ or $1^{\circ} \times 1^{\circ}$ of latitude $\times$ longitude), and observed data are valid for the location of the weather station (one point). Maximum distance between grid point and weather station for this latitude is up to 30 or $60 \mathrm{~km}$ in the case of GISS database. For our evaluation the Kvikkkjokk weather station, as a temperature reference data set, is $11.6 \mathrm{~km}$ away from the nearest grid point of gridded databases and for Tjaamotis station (precipitation reference data) it is $9.4 \mathrm{~km}$. The final values of the errors of the analyzed databases are presented in Tables 2 and 3.

In the case of mean temperature, T_CRU data set as well as T_CRUagr underestimated the monthly as well as seasonal data by $1.43{ }^{\circ} \mathrm{C}$, and seasonal data LT by $1.39^{\circ} \mathrm{C}$, as documented by the values of mean error $(\bar{e})$ in Table 2 . The significance of bias was proved with the statistical test at $\alpha=1 \%$ significance level. GISS data set was biased the least $\left(-0.15^{\circ} \mathrm{C}\right)$ due to its use of anomalies rather than absolute values. However the significance at $1 \%$ level was also proved because of big sample size $(n=1200)$. For the purpose of differences calculation, the GISS anomalies were recalculated to absolute values using Kvikkjokk data set for reference period 1950-1981 (Hansen et al., 2010).

The random error was quantified with the standard error of differences (SE). It describes the variation of the differences around the average difference $\bar{e}$ and it is considered a measure of precision of the modeled temperature data sets. The precision of the modeled monthly temperatures was found to be $\pm 0.69^{\circ} \mathrm{C}( \pm 27.26 \%)$ for T_CRU data and $\pm 1.56^{\circ} \mathrm{C}$ $( \pm 126 \%)$ for GISS data. Precision of the seasonal data was $\pm 1.19^{\circ} \mathrm{C}( \pm 46.49 \%)$ for LT data and $\pm 1.17^{\circ} \mathrm{C}( \pm 46.57 \%)$ for T_CRU $U_{\text {agr }}$ data set. The comparison of the relative standard errors shows that the monthly temperature data were approximately by $50 \%$ more precise than the seasonal data. However, this comes from the fact that SE of the seasonal data was calculated from the differences, the number of which was probably two thirds smaller $(n=400)$ than the amount of the monthly data $(n=1200)$. The advantage of the database of the modeled seasonal temperatures is that it encompasses the reconstructed time series of more than 500 years (starting in the year 1500). If it had been possible to calculate the differences for such a long time series, the mean error of the seasonal data would have probably decreased.

The overall accuracy (RMSE) of the modeled monthly temperature data sets was \pm 1.59 and $\pm 1.57^{\circ} \mathrm{C}$, and of the modeled seasonal temperature data it was \pm 1.83 and $\pm 1.85^{\circ} \mathrm{C}$ respectively.

Table 3 presents the statistical comparison of the differences between the observed and the modeled data of monthly and seasonal precipitation totals. 
Similar to temperature, the results of the statistical test proved a systematic deviation of the modeled data from the observed data. On the contrary to temperature, the modeled precipitation data sets mostly overestimated the observed records. In the monthly database, the P_CRU data biased the records by $4.62 \mathrm{~mm}(11 \%)$ on average, while in the case of seasonal data the overestimation was $15.75 \mathrm{~mm}(12.5 \%)$ for

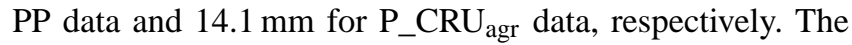
only GPCC data were underestimated by $0.73 \mathrm{~mm}$. Bigger deviation of the seasonal data results from the nature of the data, since they were calculated as a sum of precipitation of 3 months in one season.

The standard error of the monthly precipitation data sets were $\pm 5.12 \mathrm{~mm}( \pm 11 \%)$ for P_CRU and $\pm 6.77 \mathrm{~mm}$ $( \pm 16 \%)$ for GPCC. The precision of seasonal data sets amounted to $\pm 31.84 \mathrm{~mm}( \pm 22 \%)$ for PP and $\pm 17.05 \mathrm{~mm}$ $( \pm 12 \%)$ for P_CRUagr data, respectively. The final accuracy of the modeled monthly and seasonal data sets of precipitation totals is presented in Table 3.

Based on results presented in Table 3, we conclude 99\% confidence that the modeled data of both climatic variables were significantly different from the observed data. This bias can be eliminated from the data by extracting the mean deviation value $(\bar{e})$ from every value of the modeled climatic series. Bigger variability of differences for modeled and observed data around its average difference was found in GISS temperature data set $( \pm 126 \%)$.

Question 2: how does the tightness of correlation change between modeled and observed climate data sets with increasing distance of weather station from the locality of radial increment formation? Does this correlation decrease faster with increasing distance of weather station for precipitation data sets due to its higher spatial variability compared to temperature?

At this section of results the correlation was examined between the monthly data observed at the weather stations and the modeled data generated for the location of Hårås by the KNMI Climate Explorer application. The correlation was examined on the sample size 1056 records. We investigated the correlation changes for modeled data with increasing distance of the weather station to the Hårås locality.

The relationship between the monthly temperatures of various climate databases is shown in Fig. 3a. For the both modeled data (T_CRU, GISS) we revealed equal strength of correlation $(r=0.99)$ within the data $\left(T_{-} 40, T_{-} 70\right)$ of both weather stations (Kvikkjokk, Jokkmokk) located 40 and $70 \mathrm{~km}$ from Hårås. It means that $98 \%\left(r^{2}=0.98\right)$ of variability of modeled temperature data can be explained by data of both used weather stations and the increasing distance of about $30 \mathrm{~km}$ between weather stations does not significantly influence the tightness of correlation.

The correlation between the databases of monthly precipitation totals was lower than that of temperature. The variance of the modeled precipitation data sets (P_CRUGPCC) explained by the data observed at four weather stations ( $\mathrm{P}_{-} 18$,

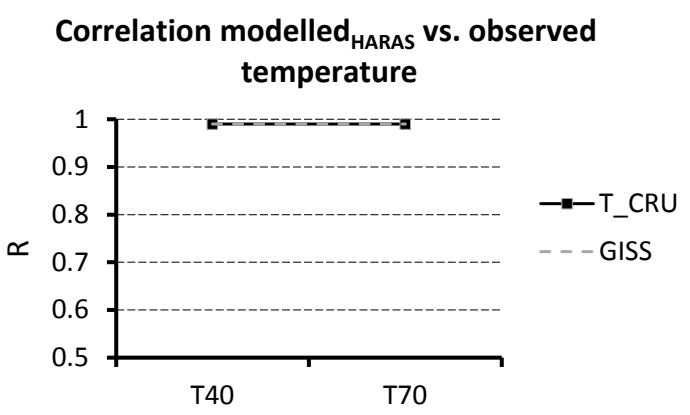

(a) Observed weather_station

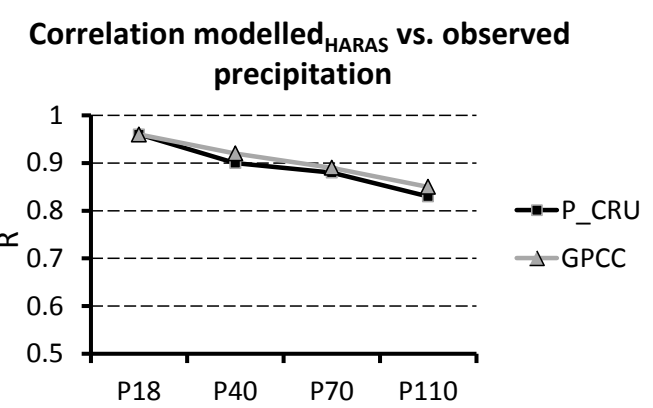

(b) Observed weather station

Figure 3. Change of correlation coefficients between (a) modelled monthly temperatures for Haras locality (T_CRU and GISS) and observed monthly temperatures (T40 and T70), (b) modelled monthly precipitation for Haras locality (P_CRU and GPCC) and observed monthly precipitation (P18, $\mathrm{P} 40, \mathrm{P} 70$ and $\mathrm{P} 110)$, related to increasing distance of weather stations from Haras locality.

P_40, P_70, P_110) was decreasing with increasing distance to the Hårås locality, as documented in Fig. 3b. The highest correlation coefficient $(r=0.96)$ was explored for the both modeled data sets in relation to the Tjaamotis station, located $18 \mathrm{~km}$ away from Hårås. Increasing distance to Kvikkjokk station $(40 \mathrm{~km})$ resulted in a lower correlation ( $r=0.90$ for P_CRU and $r=0.92$ for GPCC). Decreasing trend of correlation coefficients continues with the increase of distance $(70 \mathrm{~km})$ for Jokkmokk station to $r=0.88$ (P_CRU) and $r=0.89$ (GISS) respectively. The lowest correlation ( $r=0.83$ for P_CRU and $r=0.85$ for GPCC) was revealed with the precipitation data of the farthest weather station located in Kiruna, $110 \mathrm{~km}$ from Hårås. All differences between correlation coefficients for both model data sets were confirmed as statistically significant at the significant level $1 \%$, except for the difference between P_40 and P_70 data related to the P_CRU data set. This difference is significant at $\alpha=3 \%$. Results of temperature relationship mentioned above, together with results of decreasing correlation of precipitation data with increasing distance of weather stations confirm the well-known knowledge about 
Spruce - growth response to temperature
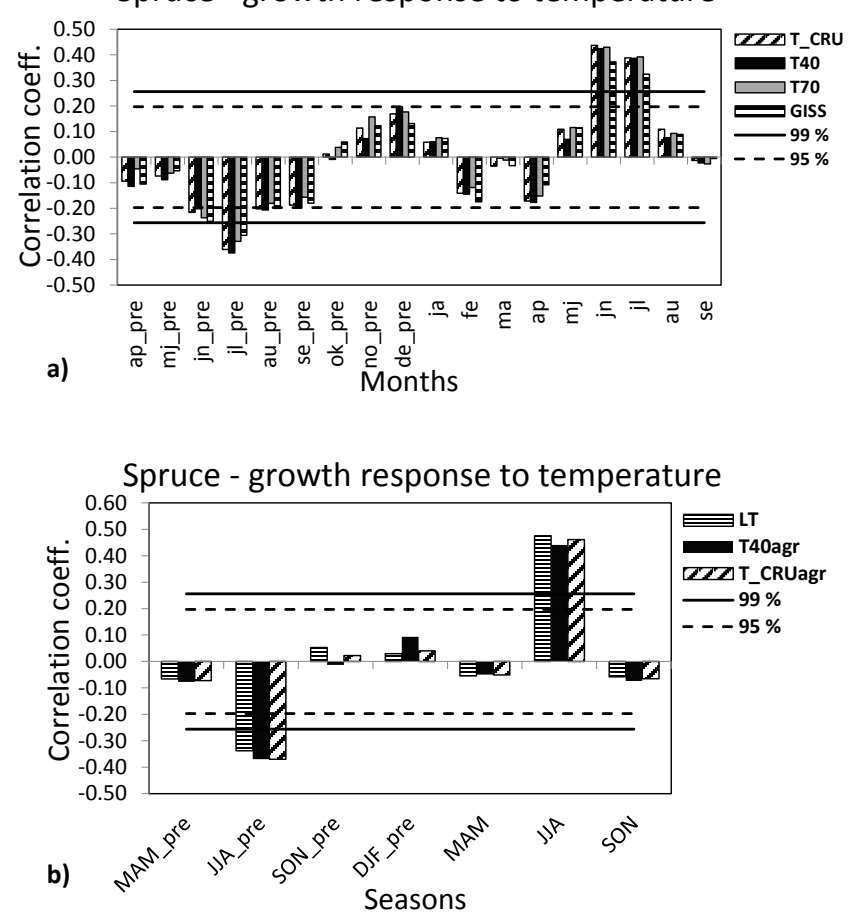

Figure 4. Growing response of spruce radial increment to data sets of (a) monthly mean temperature, (b) seasonal mean temperature.

greater spatial variability of precipitation variable compared to temperature.

\subsection{Comparing the suitability of the climatic databases for dendroclimatic analyses}

Question 3: what is the growing response of spruce to monthly and/or seasonal temperature and precipitation? The climate of which months and/or seasons is significant (positively or negatively) for radial increment formation? Which of the two examined climatic variables is the more important factor for radial increment formation? Are there any significant differences between climate databases regarding the analysis of growing response of spruce?

Derived mean indexed chronology from measured treering widths (radial increment) of spruce are considered a reference data for comparison of suitability of climate databases for dendroclimatic analysis. Eighteen individual tree-ring series with GLK $>70 \%$ were selected to derive mean chronology. The check of measured series in software COFECHA has detected no crucial errors and misdated series. Series inter-correlation of mean chronology was 0.729 and average mean sensitivity 0.204 . Based on the statistics, we consider cross-dating process to be successful enough and derived mean indexed chronology has a high potential for extraction of climate signal.
The first step was to evaluate the cross-correlation function derived from the mean indexed chronology and individual climate data sets. The values of correlation coefficients presented in Fig. 4 quantify the tightness and the trend of the relationship between the indices of radial increment and the mean of monthly (Fig. 4a) or seasonal (Fig. 4b) temperatures within the 18-month long or 7-season long dendroclimatic year. The values of the correlation coefficients were tested at $\alpha=1$ and $5 \%$ significance level.

From Fig. 4a we can see that the radial increment was significantly negatively correlated with the temperatures in June and August of the preceding year at the level $\alpha=5 \%$ and in July of the preceding year at $1 \%$ significance level. This means that with $99 \%$ confidence, high values of temperatures in July of the preceding year negatively affected increment formation in the next year. On the other hand, temperatures in the summer season in the year of increment formation were positively correlated with the amount of increment. Particularly June and July were the months that significantly promoted the formation of the radial increment at $1 \%$ significance level. However, the differences between growth responses of spruce depending on the database used were not revealed with only two exceptions. The exceptions were presented in the observed data set T_40 and T_70. August of preceding year for T_70 was not considered significant $(r=0.18)$ for radial increment formation in contrast with all the other databases and vice versa; December of the preceding year was significant at $\alpha=5 \%$ but only for T_40 data set $(r=0.20)$. Real differences of the correlation coefficients with the other databases, however, were less than $\Delta r \leq 0.03$ (August_preceding) and $\Delta r \leq 0.07$ (December_preceding) respectively.

Similar results can be interpreted from Fig. 4b. Aggregation of monthly climate data to the seasons has removed the small differences between databases in the months mentioned above. The radial increment is significantly negatively affected $(\alpha=1 \%)$ by high temperatures in the season JJA of preceding year and vice versa; it is significantly positively affected by JJA temperature in the year of increment formation. No differences in interpreting the growth response of spruce were found and no significant differences between the values of correlation coefficients depending on used climate database were detected.

The evaluation of the growth response of spruce to precipitation showed an opposite trend compared to temperature. The increasing amount of precipitation in the spring season (MAM_pre) of the preceding year positively correlated with the radial increment (Fig. 5b), and its impact on increment formation was confirmed with $95 \%$ confidence. This result was found using a PP database. Data sets from the remaining three seasonal databases did not confirm the positive impact of precipitation in the spring of the previous year. In the year of the increment formation, the amount of precipitation in the summer season (JJA) had a significant $(\alpha=5 \%)$ negative impact on increment formation. This conclusion is con- 


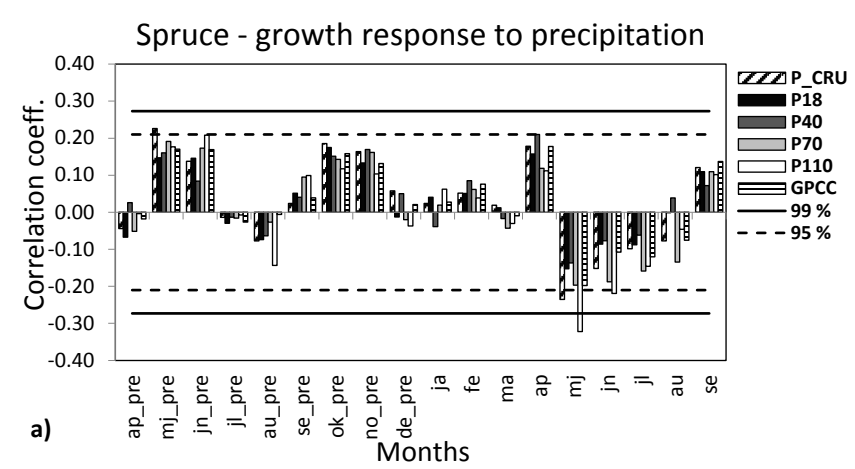

Spruce - growth response to precipitation

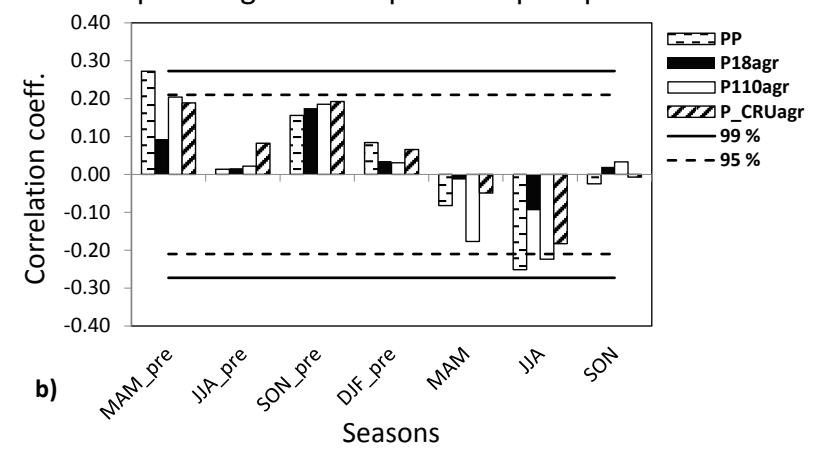

Figure 5. Growing response of spruce radial increment to data sets of (a) monthly precipitation totals, (b) seasonal precipitation totals.

firmed by two of the four compared data sets, namely modeled PP data and observed P_110agr data set. It is a surprising finding since the data observed the furthest away $(110 \mathrm{~km})$ from the locality of increment formation were more tightly correlated $(r=-0.25)$ with data observed $18 \mathrm{~km}$ from Hårås $(r=-0.09)$.

Monthly precipitation databases most closely correlate with the radial increment in May of the preceding year and in May and June the year of increment formation. For all those months and concerned data sets, the significant effect on increment formation was confirmed at $5 \%$ significance level or even at $1 \%$ level for the May of the actual year (Fig. 5a).

Regarding the interpretation of the growth response of spruce to precipitation within the mentioned significant months, its significance confirmed only two of the six data sets (Fig. 5a), modeled P_CRU and observed P110 data set. The result observed on seasonal precipitation totals was repeated itself for P110 data set. The overall highest correlation coefficient $(r=-0.32)$, i.e. in May of the actual year, occurred for the data observed at the most remote station (Kiruna), while precipitation at the nearest station (Tjaamotis) correlated only with $r=-0.15$.

The highest difference between correlation coefficients derived with all six precipitation data sets for 1 month was $\Delta r=0.18$. With sample size equaled 88 records per month, the difference is statistically significant at $\alpha=0.22$. There-
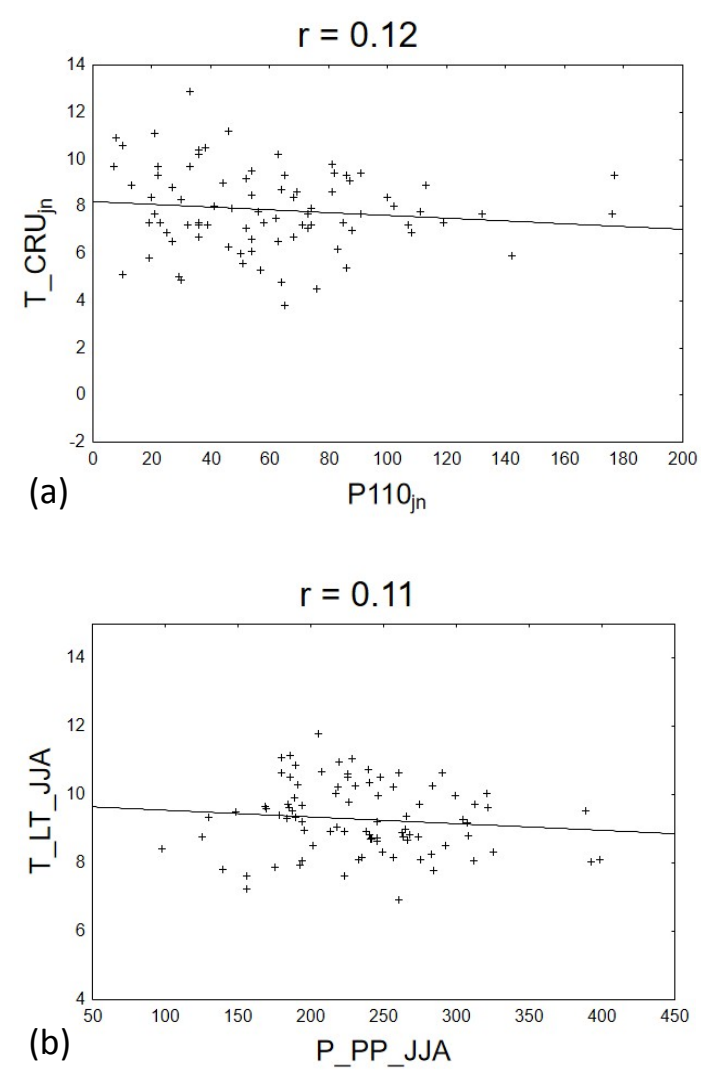

Figure 6. Correlation between temperature and precipitation common with overlapping (a) month (June), (b) season (JJA) significant for radial increment formation. Low correlation between the climatic variables in both cases $(r=0.12$ and $r=0.11)$ confirms that climate regime for growing processes of spruce is not an inversely proportional function of precipitation and temperature.

fore no significant difference of correlation coefficients could be recognized at conventional significance levels $\alpha=5 \%$ or $\alpha=1 \%$. This applies to all differences derived on the base of cross-correlation functions of all temperature and precipitation data sets examined at our study.

Higher correlation coefficients derived by crosscorrelation function for the average temperature within the area of interest point to it as more limiting factor for the radial increment formation of spruce compared to precipitation. The highest correlation coefficient $r=0.44$ for monthly temperature data was obtained from a modeled T_CRU data set in June and from an LT data set in the JJA season as $r=0.48$. For comparison, the correlation of increment and precipitation rendered the highest correlation coefficients $r=-0.32$ in May as mentioned above and $r=0.27$ for modeled PP data set in the MAM season of the preceding year.

Question 4: what is the correlation between temperature and precipitation in months and seasons which were shown significant for radial increment formation? 
For the monthly data sets, temperature and precipitation have inverse trends with regard to increment formation in June (Figs. 4a and 5a). Similarly inverse trend could be observed for the JJA season (Figs. $4 \mathrm{~b}$ and $5 \mathrm{~b}$ ). We investigated climate regime of the study area by correlating mean temperature and precipitation totals from the data sets with the tightest relationship to radial increment formation (Fig. 6a and b). Low correlation between the climatic characteristics in both cases $(r=0.12$ and $r=0.11)$ confirms that climate regime for growing processes of spruce is not inversely proportional function of precipitation and temperature.

\section{Discussion and conclusions}

Our suitability assessment of different climate databases for the purpose of dendroclimatic analyzes was based on exploring the relationships between variability of climate data and measured radial increment of spruce. Differences between the absolute values of the climatic variables (temperature, precipitation) of gridded databases and data observed at the weather stations (Kvikkjokk and Tjåmotis) were also evaluated. It was revealed that all four gridded databases of temperature and four databases of precipitation had systematic errors of different magnitude. All modeled temperature data sets underestimated the values observed at the Kvikkjokk station. The lowest bias $\left(-0.15^{\circ} \mathrm{C}\right)$ was found in the GISS database. This low value is due to the fact that the GISS database unlike the other ones contains anomalies of temperature and absolute values have been recalculated using data of Kvikkjokk station.

On the contrary, the precipitation databases, except for GPCC, overestimated the data observed at Tjåmotis precipitation station. GPCC underestimated observed monthly precipitation totals by the lowest mean error $-0.73 \mathrm{~mm}$ and the lowest bias $(14.1 \mathrm{~mm})$ among examined seasonal databases, as seen in aggregated CRU database of precipitation totals (P_CRUagr).

We assume that the different scale of information provided by gridded database and observed data set is the main source of the bias. Depending on the grid resolution, the values in the gridded database represent uniform values for the whole grid square of $0.5^{\circ} \times 0.5^{\circ}$, or $1^{\circ} \times 1^{\circ}$ for GISS, respectively, although in reality there are differences in the values of climatic variables also inside such area. For the purposes of the application of the absolute values of climatic variables, e.g. finding the optimal climatic conditions for the radial increment formation, it is possible to use any of the modeled data sets. But it is necessary to identify and eliminate its systematic error. Bias can be extracted from the databases by subtracting the mean error from every value in the database.

In case of availability of satisfactory reference data, the database containing anomalies of climatic variables enables another method of bias elimination, such as the GISS database of temperature anomalies used in our work. The cli- mate data expressed in this way enable a significant reduction or even a complete elimination of systematic errors from the modeled data. Some more databases containing temperature anomalies can be found at the KNMI Climate Explorer, for example CRUTEM 4.2.0.0 (Osborn and Jones, 2014) and HadCRUT4 (Morice et al., 2012). The disadvantage of those databases is lower grid resolution of $5^{\circ} \times 5^{\circ}$. Here it is necessary to note that the bias of climate data does not affect the evaluation of the growth response of spruce. In order to correctly assess the impact of temperature and precipitation on the formation of radial increment it is important to ensure that the variability of the time series of the considered climatic variables corresponds with the variability of the climate at the place of increment formation.

Due to this fact, we analyzed the correlation of the examined climate variables between all modeled monthly data generated for point of grid with location of Hårås and the data observed at the nearby weather stations. The comparison revealed that the modeled precipitation data correlated less than the temperature data at all four precipitation stations. It must be pointed out, however, that the nearest precipitation station was only $18 \mathrm{~km}$ away from Hårås, while the nearest station with the observed temperature was at a distance of $40 \mathrm{~km}$. Decreasing trend of correlation coefficients with increasing distance $(18,40,70,110 \mathrm{~km})$ of precipitation stations, together with stable values of correlation coefficients for temperatures observed 40 and $70 \mathrm{~km}$ from Håra (Fig. 3) confirmed the well-known fact that precipitation is in the space more variable than temperature. This is also accounted for during the development of modeled climate databases. For example, the interpolation of precipitation values was performed within a smaller radius per one grid point than the interpolation of temperatures in CRU database. In the case of precipitation, the correlation decreases faster as the distance increases, which is expressed by CDD (correlation decay distance) value during the selection of the stations for the interpolation of the grid point (Harris et al., 2014).

Comparison of effects of both climatic variables on the creation of radial increment of spruce has confirmed the dominance of the temperature signal. This is in coincidence with the results of Babst et al. (2013), who among others evaluated the impact of precipitation and temperature on spruce increment formation in the boreal zone of northern Scandinavia.

In terms of interpreting the growth response of spruce using multiple temperature databases, significant differences between them were not detected. With $99 \%$ confidence the temperature affected the increment formation of spruce within 3 months of dendroclimatic year. June of the preceding year was confirmed as a month with negative influence and higher temperature in June and July in the year of increment formation supports the growth of spruce positively. From the point of evaluating the possible use of different temperature databases for the explanation of the growth response we did not find any significant differences between 
the observed and the modeled data. We can recommend CRU database for dendroclimatic analysis when observed data are not available. GISS database did not demonstrate statistically significant difference, but the trend in lower correlation coefficients in all 3 months responsible for the increment formation may relate to lower grid resolution of the database $\left(1^{\circ} \times 1^{\circ}\right)$. Confirmation of that hypothesis has to be examined by further research.

Also the evaluation of seasonal temperature databases did not show any significant differences in growth response of spruce compared with observed data and therefore Luterbacher et al. (2004) database and aggregated database of CRU can also be recommend for their use in dendroclimatic analysis.

The growth response of spruce to precipitation totals was less definite. The significance of correlation coefficients for relation precipitation versus increment was confirmed just with $95 \%$ confidence and only for two of six examined databases of monthly precipitation. CRU database positively correlated with increment in May of the preceding year and negatively in May of the year of increment formation. The same negative correlation was observed in the data set of the Kiruna weather station located 110 km from Hårås. In addition, a significant negative correlation was established for it in June.

Although the differences between correlation coefficients of the precipitation databases are bigger than those of temperature databases, none of them can be considered at a confidence level higher than $78 \%$. Therefore none of them can be singled out as the best option. However, it can be seen that the correlation coefficients of modeled databases range between coefficients of observed data sets. Based on our results we recommend that, within areas featuring only a sparse network of weather stations, examined precipitation gridded databases (CRU, GPCC) can be employed for the purpose of dendroclimatic analysis.

It was shown that in two seasons with significant correlations (spring of the preceding year and summer of the current year), the PP gridded database reached the highest correlation coefficient despite the fact that none of the data observed achieved such high coefficients. This could be due to the fact that PP database represents a restored 502-year long database, created by means of dendrochronological data (Pauling et al., 2006) as well. Because of that, using this database in dendroclimatic analysis could overestimate correlations concerning the radial increment formation of trees, but it should be inspected in more detail.

Finally, based on our results we could not reject the hypothesis that the climate data from the nearest weather stations are the most suitable for the purposes of dendroclimatic analysis. This is particularly true for precipitation data that are more variable in space than temperature.

\section{Data availability}

The data sets of the gridded climate databases are publicly available for; CRU TS 3.23 (Harris et al., 2014) at https://crudata.uea.ac.uk/cru/data/hrg/cru_ts_3.23/, for GISS $250 \mathrm{~T} 2 \mathrm{~m} / \mathrm{SST}$ anom (Hansen et al., 2010) at https://climexp.knmi.nl/select.cgi?id=someone@ somewhere\&field=giss_temp_250, for Luterbacher et al. Temperature (Luterbacher et al., 2004) at https: //crudata.uea.ac.uk/cru/projects/soap/data/recon/\#luter04, for CPCC V7 (Schneider et al., 2015) at ftp://ftp.dwd.de/ pub/data/gpcc/html/fulldata_v7_doi_download.html and Pauling et al. Precipitation (Pauling et al., 2006) at https: //www.ncdc.noaa.gov/cdo/f?p=519:1:::::P1_study_id:6342.

\section{The Supplement related to this article is available online at doi:10.5194/esd-7-385-2016-supplement.}

Acknowledgements. This work was accomplished as a part of the projects of the Scientific grant agency of the Ministry of Education of the Slovak Republic, VEGA no.: 1/0281/11, 1/1130/12, 1/0008/13, 1/0463/14, 2/0101/14, 1/0589/15, 1/0367/16 and the projects of the Slovak Research and Development Agency no.: APVV-0423-10, APVV-0131-11, APVV-0303-11, APVV0480-12 and APVV-0069-12. The authors thank the agencies for the support.

Edited by: C. Franzke

\section{References}

Babst, F., Poulter, B., Trouet, V., Tan, K., Neuwirth, B., Wilson, R., Carrer, M., Grabner, M., Tegel, W., Levalic, T., Panayotov, M., Urbinaci, C., Bouriaud, O., Iais, P., and Frank, D.: Site and species-specific responses of forest growth to climate across to European continent, Global Ecol. Biogeogr., 22, 706-717, 2013.

Büntgen, U., Esper, J., Verstege, A., Nievergelt, D., Frank, D. C., and Wilson, R. J. S.: Growth responses to climate in a multispecies tree-ring network in Western Carpathian Tatra Mountains, Poland and Slovakia, Tree Physiol. 27, 689-702, 2007.

Büntgen, U., Franke, J., Frank, D., Wilson, R., González-Rouco, F., and Esper, J.: Assessing the spatial signature of European climate reconstructions, Clim. Res., 41, 125-130, 2010.

Büntgen, U., Kyncl, T., Ginzler, C., Jacks, D. S., Esper, J., Tegel, W., and Kyncl, J.: Filling the Eastern European gap in millenniumlong temperature reconstructions, P. Natl. Acad. Sci. USA, 110, 1773-1778, 2013.

Climexp.KNMI: Climate explorer, http://climexp.knmi.nl, last access: 18 April 2014.

Cook, E. R. and Kairiukstis, L. A.: Methods of Dendrochronology: Aplications in the Environmental Sciences, Dordrecht: The International Institute for Applied Systems Analysis, 394 pp., 1990.

Cowtan, K. and Way, R. G.: Coverage bias in the HadCRUT4 temperature series and its impact on recent temperature trends, Q. J. Roy. Meteor. Soc., 140, 1935-1944, 2014. 
Cropper, J. P.: Tree-ring skeleton plotting by computer, Tree-Ring Bulletin, 39, 47-54, 1979.

Gouirand, I., Linderholm, H. W., Moberg, A., and Wohlfarth, B.: On the spatiotemporal characteristics of Fennoscandian tree-ring based summer temperature reconstruction, Theor. Appl. Climatol., 91, 1-25, 2007.

Grissino-Mayer, H. D.: Evaluating crossdating accuracy: Manual and tutorial for the computer program COFECHA, Tree-Ring Res., 57, 205-221, 2001.

Grudd, H., Briffa, K. R., Karlén, W., Bartholin, T. S., Jones, P. D., and Kromer, B.: A 7400-year tree-ring chronology in northern Swedish Lapland: natural climatic variability expressed on annual to millennial timescales, Holocene, 12, 657-667, 2002.

Hansen, J., Ruedy, R., Sato, M., and Lo, K.: Global surface temperature change, Rev. Geophys., 48, RG4004, doi:10.1029/2010RG000345, 2010.

Harris, I., Jones, P. D., Osborn, T. J., and Lister, D. H.: Updated high-resolution grids of monthly climatic observations - the CRU TS3.10 Dataset, Int. J. Climatol., 25, 623-642, doi:10.1002/joc.3711, 2014.

Haylock, M. R., Hofstra, N., Klein Tank, A. M. G., Klok, E. J., Jones, P. D., and New, M.: A European daily high-resolution gridded dataset of surface temperature and precipitation, J. Geophys. Res.-Atmos., 113, D20119, doi:10.1029/2008JD010201, 2008.

Holtmeier, F. K. and Broll, G.: Sensitivity and response of northern hemisphere altitudinal and polar treelines to environmental change at landscape and local scales, Global Ecol. Biogeogr., 14, 395-410, 2005.

Luterbacher, J., Dietrich, D., Xoplaki, E., Grosjean, M., and Wanner, H.: European Seasonal and Annual Temperature Variability, Trends, and Extremes Since 1500, Science, 303, 1499-1503, doi:10.1126/science.1093877, 2004.
Mitchel, T. D. and Jones, P. J.: An improved method of constructing a database of monthly climate observations and associated highresolution grids, Int. J. Climatol., 25, 693-712, 2005.

Morice, C. P., Kennedy, J. J., Rayner, N. A., and Jones, P. D.: Quantifying uncertainties in global and regional temperature change using an ensemble of observational estimates: The HadCRUT4 data set, J. Geophys. Res., 117, 1-22, 2012.

Osborn, T. J. and Jones, P. D.: The CRUTEM4 land-surface air temperature data set: construction, previous versions and dissemination via Google Earth, Earth Syst. Sci. Data, 6, 61-68, doi:10.5194/essd-6-61-2014, 2014.

Pauling, A., Luterbacher, J., Casty, C., and Wanner, H.: Five hundred years of gridded high-resolution precipitation reconstructions over Europe and the connection to large-scale circulation, Clim. Dynam., 26, 387-405, doi:10.1007/s00382-005-0090-8, 2006.

Schneider, U., Becker, A., Finger, P., Meyer-Christoffer, A., Rudolf, B., and Ziese, M.: GPCC Full Data Reanalysis Version 7.0 at $0.5^{\circ}$ : Monthly Land-Surface Precipitation from Rain-Gauges built on GTS-based and Historic Data, doi:10.5676/DWD_GPCC/FD_M_V7_050, 2015.

Tuomenvirta, H., Drebs, A., Førland, E., Tveito, O. E., Alexandersson, H., Laursen, E. V., and Jónsson, T.: Nordklimdata set 1.0, KLIMA Report no. 08/01, DNMI, 26 pp., http://www.smhi. se/hfa_coord/nordklim/index.php?page=dataset (last access: 16 January 2016), 2001.

Wang, X., Zhao, X., and Gao, L.: Climatic response of Betula ermanii along an altitudinal gradient in the northern slope of Changbai Mountain, China, Dendrobiology, 70, 99-107, 2013. 